\title{
HISTIOCITOSE DE CÉLULAS DE LANGHERHANS. RELATO DE CASO
}

\section{LANGERHANS CELL HISTIOCYTOSIS. CASE REPORT}

\author{
DOI: $10.5380 /$ rmu.v1i2.40705
}

João Vitor Bacarin ${ }^{1}$, Pedro Henrique Isaacsson Velho ${ }^{1}$, Augusto Passoni Slovinski ${ }^{1}$, Gibran Avelino Frandoloso ${ }^{1}$, Mauricio de Carvalho' ${ }^{1}$.

\section{RESUMO}

Introdução: As células de Langerhans são encontradas na epiderme, nas células interdigitais dos linfonodos, no timo, no epitélio mucoso gastrointestinal e respiratório e na cérvice; mantendo função de células apresentadoras de antígenos. A Histiocitose de células de Langerhans é caracterizada por uma proliferação anormal de histiócitos. A doença pode ser localizada ou disseminada, envolvendo dois ou mais sistemas. A Histiocitose das células de Langerhans pulmonar é uma condição rara que acomete principalmente homens jovens e tabagistas. Relato: Paciente do sexo masculino, 27 anos, branco, trabalhador da construção civil, apresentou há dois anos dispnéia que evoluiu com piora progressiva. Há seis meses evoluiu com tosse seca, febre, sudorese noturna, dor torácica ventilatório-dependente, ganho de peso de cerca de $10 \mathrm{~kg}$. A tomografia computadorizada de tórax demonstrou padrão de múltiplos nódulos e cistos que poupavam os seios costofrênicos. O lavado bronco alveolar revelou predomínio de macrófagos. Teste de restrição hídrica positivo para diabetes insipidus de origem central. O paciente foi diagnosticado com a forma pulmonar da histiocitose de células de Langerhans associado a diabetes insipidus central. Conclusão: A Histiocitose de células de Langerhans é uma doença rara que pode ter acometimento de múltiplos sistemas. Na presença de manifestação clínica em um sítio deve-se proceder a investigação de outros possíveis focos da doença.

Palavras-Chave: Histiocitose X, Histiocitose de Células de Langerhans, Pneumopatias, Pulmão

\section{ABSTRACT}

Introduction: Langerhans cells are found at epidermis, at lymp nodes' interdigital cells, thyme, gastrointestinal and respiratory mucosa and cervix; working as antigen presenting cells. Langerhans cell histiocytosis is characterized by the abnormal histiocytes proliferations. The desease could be restricted or disseminates, involving two or more systems. Pulmonary Langerhans cell histiocytosis is a rare condition affecting Young men and smokers. Report: White man, 27 years old, bricklayer, refers progressive cough, ventilatory chest pain and $10 \mathrm{~kg}$ weight gain. Chest computerized tomography shows multiple nodes and cysts sparing costphrenic sinuses. Broncho alveolar labage reveals macrophage predominance. Water restriction test was positive for central insipidus diabetes. Conclusão: Langerhans cell hystiocytosis is a rare syndrome that could affect multiple systems. For this reason if we have clinical anifestation in one organ we should purse it in other sites.

Key Words: Histiocytosis X; Langerhans Cell Histiocytosis; Pneumopathy; Lung 


\section{INTRODUÇÃO}

O termo Histiocitose $X$ foi introduzido em 1953 por Lichenstein na tentativa de caracterizar um espectro de doenças como sendo originários de um distúrbio comum - a proliferação anormal das células de Langerhans ${ }^{1}$.

As células de Langerhans foram primeiramente descritas em 1868 por Paul Wilheim Heinrich como células dendríticas epidérmicas. $O$ autor acreditava que estas células eram receptores nervosos sensoriais intraepidérmicos. Porém, estudos posteriores descartaram esta associação ${ }^{2}$.

A histiocitose é caracterizada por proliferação anormal de histiócitos. Estas células são tipicamente encontradas na epiderme, nas células interdigitais dos linfonodos, no timo, epitélio mucoso gastrointestinal e respiratório e na cérvice. Elas possuem função de células apresentadoras de antígenos ao sistema imune ${ }^{2}$.

A causa e a fisiopatologia da doença permanecem incertas. Uma das teorias afirma ser resultante de desordem na regulação do sistema imune $^{2}$. A doença manifesta-se pelo aparecimento de lesões na pele, nos ossos, no fígado, baço, sistema nervoso central, linfonodos e nos pulmões ${ }^{3}$. O envolvimento ósseo, isolado ou concomitante a lesões em outros sítios, é a apresentação mais comum da histiocitose $X^{4}$. A doença pode ser localizada, conferindo excelente prognóstico, ou disseminada, envolvendo dois ou mais sistemas. A doença disseminada, quando envolve órgãos de risco e/ou ocorre em menores de dois anos de idade, pode apresentar curso devastador, com potencial evolução para o óbito 5 .

Geralmente é diagnosticada na infância, com pico de incidência na primeira década de vida ${ }^{4}$. A incidência anual varia entre 0,5 a 5,4 milhões de crianças/ano, com predileção pelo sexo masculino.

\section{RELATO DO CASO}

Paciente do sexo masculino, 27 anos, branco, trabalhador da construção civil, admitido na Clínica Médica do HC-UFPR com queixa de dispneia de início há dois anos, que evoluiu progressivamente dos grandes esforços aos pequenos esforços. Há seis meses apresentou tosse seca, cerca de cinco episódios ao dia e que há dois meses tornou-se produtiva com expectoração esverdeada em pequena quantidade, sem hemoptise associada. Houve também episódios de febre vespertina e sudorese noturna. O paciente relatava ainda dor torácica ventilatório-dependente em região paravertebral, localizada em terço médio do tórax. Ao realizar esforço físico, a dor se acentuava, adquirindo padrão latejante e acometendo todo o tórax. Na revisão de sistemas, referia ganho de peso de cerca de $10 \mathrm{~kg}$. Tabagista 18 anos/maço, ex-usuário de crack, 20 gramas por semana por 4 anos e maconha. Apresentava ainda elevada ingesta hídrica, com cerca de 5 litros/dia.

Ao exame físico apresentava cianose labial, estava afebril, frequência respiratória de 28 ciclos/minuto, oximetria de pulso de $83 \%$ em ar ambiente. O exame torácico revelava tiragem supraclavicular, murmúrio vesicular diminuído em bases, estertoração em ápices bilateralmente, hiperfonese B2 em foco pulmonar. Notava-se ainda baqueteamento digital, unha em vidro de relógio. (Figura 1).

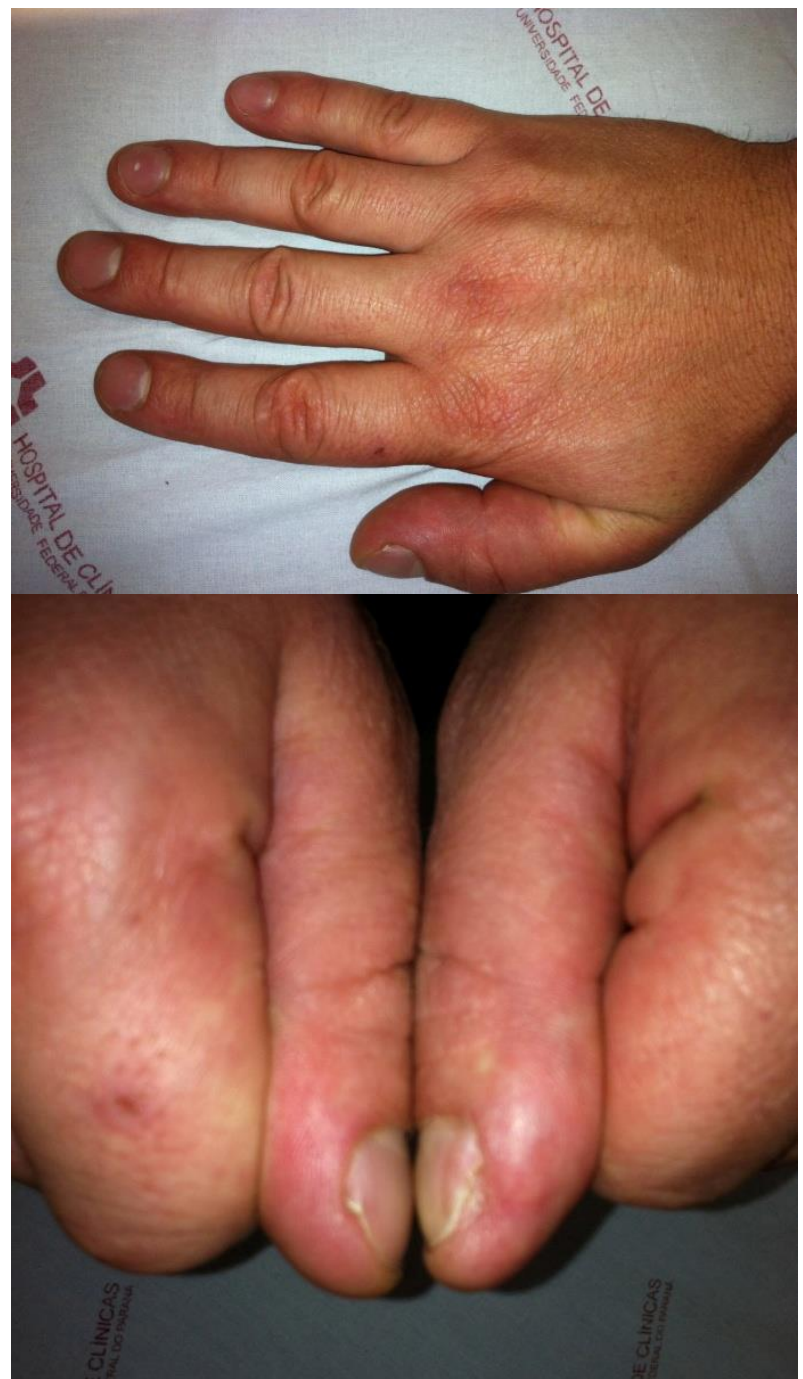

Figura 1 A - Baqueteamento digital.

Figura 1 B - Unha em vidro de relógio

A radiografia de tórax demonstrou padrão de infiltrado reticulo-nodular difuso. Os exames laboratoriais, eletrólitos, de função renal, função hepática, marcadores de inflamação, de lise celular não se monstraram alterados. As hemoculturas foram negativas para bacterias ou fungos. A gasometria arterial colhida em ar ambiente demonstrou hipoxemia moderada com $\mathrm{PaO} 2$ de $64,7 \mathrm{mmHg}$. As 
sorologias para hepatites $B$ e $C$ foram negativas assim como para o HIV. A pesquisa de BAAR em duas amostras de escarro foram negativas assim como a pesquisa para Pneumocystis jiroveci.

A tomografia computadorizada de tórax demonstrou inúmeros nódulos menores do que $5 \mathrm{~mm}$ e múltiplos cistos com paredes finas, alguns confluentes ocupando os três terços do pulmão poupando, no entanto, os seios costofrênicos. Havia também a presença de áreas em vidro fosco. (Figura 2)

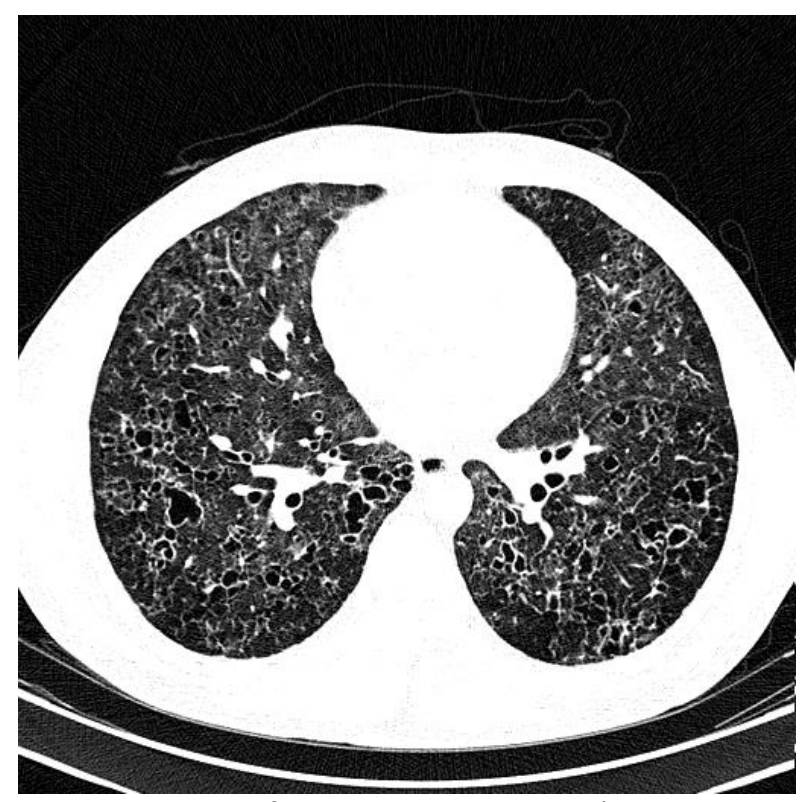

Figura 2 - Tomografia computadorizada de tórax demonstra inúmeros cistos de paredes finas, alguns confluentes, no terço médio do tórax.

0 paciente foi também submetido à espirometria de volumes e difusão, que demonstrou distúrbio ventilatório obstrutivo leve, prova broncodilatadora negativa, presença de alçaponamento de ar, além de distúrbio difusional grave. No teste de caminhada de 6 minutos, a distância percorrida foi abaixo do limite inferior da normalidade e dessaturação significativa (89\% para $85 \%)$. O ecocardiograma demonstrou hipertensão pulmonar (PSAP $=52 \mathrm{mHg}$ ) e aumento de diâmetro de câmaras direitas.

A fibrobroncoscopia com lavado broncoalveolar evidenciou predomínio de macrófagos (50\%). A coloração pelo Gram, o micológico direto e a coloração para BAAR foram negativos. Na cultura houve crescimento de Streptococcus viridans. A biópsia transbrônquica foi negativa.

Foi realizado um teste de restrição hídrica, que foi positivo para diabetes insipidus de origem central. Os níveis de TSH, T4 livre, testosterona total e prolactina estavam normais. Radiografias de mandíbula, escápulas e costelas não evidenciaram a presença de granulomas ou lesões líticas.
$\mathrm{Na}$ alta hospitalar o paciente foi orientado sobre cessação do tabagismo. A prescrição da alta incluiu: uso de oxigênio domiciliar por 18 horas/dia, prednisona $60 \mathrm{mg} /$ dia com plano de retirada gradual, DDAVP (acetato de desmopressina) nasal, vitamina D e suplementação com cálcio.

\section{DISCUSSÃO}

O diagnóstico da Histiocitose de Células de Langerhans pode ser presumido, provável ou definitivo. Este é realizado pela utilização de imunohistoquímica que identifica células de Langerhans, da detecção de CD1a na superfície da membrana das células ou através da identificação dos grânulos de Birbeck, por meio da microscopia eletrônica ${ }^{2,4}$.

O tratamento é baseado na quimioterapia, sendo os medicamentos mais estudados a vinblastina e o etoposídeo, associados ao uso de corticóides ${ }^{5}$.

A histiocitose das células de Langerhans pulmonar caracteriza uma doença intersticial ${ }^{6}$, sendo considerada uma condição rara que acomete principalmente homens entre 20 e 40 anos. Está fortemente associada ao tabagismo. As manifestações incluem: tosse, dispneia, febre e perda de peso. 0 pneumotórax pode complicar cerca de $25 \%$ dos casos $^{7}$.

O curso clínico da doença pulmonar nos adultos é variável e imprevisível, podendo ser assintomático ou rapidamente progressivo, com falência respiratória. Alguns fatores estão associados a um pior prognóstico: extremos de idade; envolvimento multissistêmico; radiografia de tórax evidenciando cistos extensos e padrão de faveolamento; capacidade de difusão do monóxido de carbono reduzida; obstrução das vias aéreas, demonstrado por uma redução na relação VEF1/CVF (volume expiratório forçado em 1 segundo/capacidade vital forçada); corticoterapia prolongada; e evidência de aprisionamento aéreo, caracterizado por aumento na relação VR/CPT (volume residual/capacidade pulmonar total) ${ }^{6}$. A cessação do tabagismo é o tratamento-chave. Porém, a maioria dos pacientes apresenta doença persistente ou progressiva ${ }^{7}$.

O envolvimento cerebral na hisitocitose $X$ é descrito principalmente em crianças. Caracteriza-se, mais comumente, por déficit funcional hipotalâmicohipofisário, secundário ao crescimento de granulomas ${ }^{8}$. O diabetes insipidus central pode ser a primeira manifestação da doença ${ }^{9}$ e é radiologicamente demonstrado pelo espessamento do halo hipofisário ${ }^{10}$. Este diagnóstico é sugerido através da Ressonância Nuclear Magnética ${ }^{3}$, sendo o achado mais precoce a perda do sinal hiperintenso da hipófise posterior em T1, o que revela a diminuição dos grânulos de estocagem do $A D H^{10}$. $\mathrm{O}$ diabetes insipidus é 
geralmente permanente, requerendo uso definitivo de vasopressina.

\section{REFERÊNCIAS}

1. The French Langerhans's Cell Histiocytosis Study Group. A multicentre retrospective survey of Langerhans'cell histiocytosis: 348 cases observed between 1983 and 1993. Archives of Disease in Childhood, n 75, p 17-24, mar 1996.

2. LEONIDAS, J. C., GUELFGUAT, M., VALDERRAMA, E. Langerhans'cell histiocytosis. The Lancet, v 361, p 1293-95, apr 2003.

3. IMASHUKU, S., SHIODA, Y., KOBAYASHI, R., HOSOI, G., FUJINO, H., SETO, S., WAKITA, H., OKA, A., OKAZAKI, N., FUJITA, N., MINATO, T., KOIKE, K., TSUNEMATSU, Y., MORIMOTO, A., JAPAN LCH STUDY GROUP. Neurodegenerative central nervous system disease as late sequelae of Langerhans cell histiocytosis. Report from the Japan LCH Study Group. Haematologica, n 93, p 615-618, 2008.

4. SINGH, T., SATHEESH, C. T., APPAJI, L., KUMARI, B. S. A., MAMATHA, H. S., GIRI, G. V., RAO, C. R. Langerhan's cell histiocytosis: A single institutional experience. Indian J Med Paediatr Oncol, n 31, ed 2, p 51-53, apr-jun 2010.

5. GARDNER, H., GROI, N., POTSCHGER, U., MINKOV, M., ARICÒ, M., BRAIER, J., BROADBENT, V., DONADIEU, J., HENTER, J., MCCARTER, R., LADISCH, S. improved outcome in multisystem Langerhans cell histiocytosis is associated with therapy intensification. Blood Journal, n 111, p 2556-2562, nov 2007.

6. VASSALO, R., RYU, J. H., SCHROEDER, D. R., DECKER, P. A., LIMPER, A. H. Clinical Outcomes of Pulmonary Langerhans'-Cell Histiocytosis in Adults. New England Journal of Medicine, n 346, p 484-490, feb 2002.

7. FAUCI, A. S., BRAUNWALD, E., KASPER, D. L., HAUSER, S. L., LONGO, D. L., JAMESON, J. L., LOSCALZO, J. Harrison's Principles of Internal Medicine, $17 \mathrm{ed}$, McGraw Hill Medical, 2008.

8. SPAGNOLO, F., LEOPIZZI, E., CARDAMONE, R., FALAUTANO, M., MARTINELLI, V., COMI, G., VOLONTÉ, M. A. Neurodegeneration in the course of Langerhans cell histiocytosis. Neurol Sci, jul 2011.

9. MARCHAND, I. BARKAOUI, M. A., GAREL, C., POLAK, M., DONADIEU, J. WRITING COMMITTEE. Central Diabetes Insipidus as the inaugural manifestation of Langerhans cell histiocytosis: medical history and medical evaluation of 26 children and adolescents. J Clin Endocrinol Metab, n 96, ed 9, p 1352-60, sep 2011.

10. REDHU, R., NADKARNI, T., MAKESH, R. diabetes insipidus associated with a thickened piyuitary stalk in a case of Langerhans Cell Histiocytosis. Journal of Pediatric Neurosciences, n 6, p 62-64, 2011. 